\title{
Noticias sobre los judíos de Candelario (Salamanca)
}

Marciano de HERVÁS

Candelario es una población de unos 1.500 habitantes situada al sur de Salamanca, en un terreno. escarpado que forma la sierra del mismo nombre, en los límites provinciales de Ávila, Cáceres y Salamanca. Desde los primeros tiempos de su fundación, aparece ligada a la jurisdicción de la villa y tierra de Béjar, a cuyo alfoz pertenece desde el siglo XIIr.

Candelario irrumpe por primera vez en las páginas de la historia en 1212, a raíz de su participación en la batalla de Las Navas de Tolosa, bajo la bandera de Alfonso viII, y en la batalla del Salado en 1340. Durante el decurso del siglo XIV el señorío de Béjar -también la aldea de Candelario- está sujeto al capricho de la monarquía, trasvasado a infantes y señores hasta que el 8 de junio de 1396 el monarca Enrique III trueca a Diego López de Estúñiga el feudo bejarano por la villa de Frías ${ }^{1}$. Desde entonces, la suerte de la tierra de Béjar y sus aldeas están ligadas al dignatario feudal. Es, precisamente, el primer señor de Béjar, Diego López de Estúñiga, quien estatuye el mayorazgo de los Zúñiga el 29 de junio de 1397 heredero en su primogénito.

En los días de gobierno del noble bejarano Diego López de Estúñiga (1396-1417) ${ }^{2}$, es muy probable que afluyera una considerable oleada inmigratoria hebrea hacia la despoblada comarca de Béjar y el suelo extremeño procedente de las juderías esquil-

${ }^{1}$ Sobre la familia Zúñiga en el ducado de Béjar véase Archivo Histórico Nacional [= AHN], Sección Nobleza, Osuna, legs. 211 a 304; otras noticias en V. Paredes, "Los Zúñigas, señores de Plasencia", Revista de Extremadura 7-11 (1903-1909).

${ }^{2}$ Hay una semblanza de su vida en Paredes "Zúñigas" 7 págs. 241-254. 
madas de Andalucía y Toledo ${ }^{3}$. Recordemos que en 1391 el foro peninsular experimenta enconadas rebeliones antijudías y destrucciones de sinagogas, que se prodigan también en Andalucía $y$, muy en particular, en la ciudad de Sevilla, a consecuencia de las prédicas incendiarias del arcediano de Écija, Ferrán Martínez.

En el extremo opuesto de la balanza, es notorio que durante los siglos XIII y XIV no es usual la presencia de comunidades hebreas en tierras de señorío, cuya actitud es considerada como una relajación del compromiso que los engarza con el protectorado regio. En este tiempo habita en la demarcación del señorío bejarano una reducida comunidad hebrea afincada en la villa de Béjar.

Sin embargo, las graves persecuciones antijudías que asolan la Península a fines de la centuria del XIV dan alas a los desplazamientos migratorios de judíos desde las grandes aljamas y juderías radicadas en los centros urbanos hacia las poblaciones rurales menos habitadas y apacibles, en un intento por rehacer su vida en el judaísmo, distanciados de los enclaves de población conflictivos. Las pequeñas aldeas de Castilla y Extremadura, que controlarán mayoritariamente la nobleza y las órdenes militares en el siglo XV, van a ser las grandes beneficiarias de este fenómeno migratorio.

Así pues, el ambiente hostil que se respira en la capital de Híspalis contra el pueblo hebreo pudo ser uno de los factores desencadenantes de la primera inmigración hebrea andaluza hacia el solar de la villa y tierra bejarana, cuyo movimiento migratorio dirige a buen seguro desde los pasillos de la Corte el noble Diego López de Estúñiga.

Además de gozar de la confianza del soberano Enrique III, Diego López de Estúñiga ostenta el cargo de Justicia Mayor de Castilla desde 1395. El 9 de enero de 1396 Diego López de Zúñiga y el mayordomo Juan Hurtado de Mendoza reciben de la monarquía, entre otras mercedes, un racimo de casas y sinagogas confiscadas a la judería de Sevilla, cuyas heredades vende a su vez Juan Hurtado al dignatario de Béjar el 26 de noviembre ${ }^{4}$. En este campo de acción, las intrigas palaciegas del primer señor de

\footnotetext{
3 J. L. LaCAve, Juderías y sinagogas españolas (Madrid 1992) págs. 391-392.

4 "Mando mas a el d[ic]ho Pedro mi fixo todas las cassas e signogas y propios que yo he en Sevilla de que el rrey mi señor fiso merced a Juan Hurtado de Mendoça y a mi, de lo qual yo conpre la su parte" (AHN, Sección Nobleza, Osuna, leg. 213, expte. 21).
} 
Béjar, unido a sus influencias en la Corte, dan cobertura a sus intereses particulares, entre los cuales despunta la política repobladora de las semidesérticas aldeas del alfoz bejarano.

Tengamos en cuenta que el primer dignatario de la villa y tierra de Béjar recibe del monarca Enrique III una serie de aldeas escasamente pobladas, que precisa repoblar con nuevos colonos. Por otro lado, en la villa bejarana, cabecera de señorío, habita desde la reconquista castellana de Alfonso VIII, a fines del siglo XII, una comunidad hebrea que practica sin problemas aparentes su fe en la ley de Moisés s. Esta comunidad hebraica bien pudo actuar de reclamo señorial para potenciar la demografía de la aljama bejarana con moradores de las maltrechas juderías andaluza y, quizá, toledana.

La calzada romana de la Plata, que liga las metrópolis de Sevilla y Gijón surcando la campiña castellana y extremeña, es el soporte viario adecuado para canalizar un segmento de la oleada migratoria hebrea hacia las poblaciones de las tierras de señorío de Castilla y Extremadura. ¿Es, quizá, en este tiempo cuando arriban las primeras familias hebreas a algunas aldeas de la villa de Béjar? La documentación de archivo no alcanza por el momento a despejar ésta incógnita. En este sentido, el repartimiento de Huete, compuesto por orden del monarca castellano Sancho IV en 1290-1291 , y las escasas noticias espigadas en el siglo XIV, sólo documentan la existencia de la aljama de Béjar y no citan ninguna otra judería o comunidad judía en la demarcación.

No hay más datos fidedignos hasta mediados del siglo XV. Con el paso del tiempo, bajo la égida del noble Álvaro I, señor de la villa y tierra de Béjar (1453-1488), se desarrolla en la comarca el modelo económico iniciado por sus antecesores. Siguiendo la política emprendedora de su padre, Pedro de Zúñiga (14171453), el dignatario Álvaro I confirma entre los años de 1456 y 1461 las ordenanzas de la feria anual de Béjar y reglamenta asimismo la contribución de los paños y las franquicias concedidas

${ }^{5}$ J. Gutiérrez Cuadrado, Fuero de Béjar (Salamanca 1977); otras noticias en C. Carrete Parrondo, Fontes Iudaeorum regni castellae: I Provincia de Salamanca (Salamanca 1981) págs. 41-54.

${ }^{6}$ M. Gaibrols, Historia de Sancho IV de Castilla, vol. 3 (Madrid 1928) doc. 322 pág. CCIV; C. Carrete, "El repartimiento de Huete», Sefarad 36 (1976) págs. 121-140: pág. 128. 
al mercado semanal de los jueves ${ }^{7}$, cuyas disposiciones contribuyen a hacer más dinámica la vida mercantil del alfoz $\mathrm{y}$, en particular, insuflan vientos renovadores a la feria de la villa, atrayendo la presencia de un contingente de mercaderes judíos ${ }^{8}$.

Al hilo del discurso, tenemos noticias de que en el ecuador del siglo XV el noble Álvaro I drena para sus arcas una serie de impuestos regios, cuales son las alcabalas, tercias, pedido judio, cabeza de pecho judío y moneda forera, cuyas rentas han sido estudiadas con amplitud por J. Martínez Moro ${ }^{9}$. Los libros de Hacienda de los Zúñiga revelan en su verdadera magnitud el perfil específico de la fiscalidad de los judíos asentados en sus territorios bejaranos en 1454, cuyas exacciones judiegas se expresan en las cantidades siguientes: cabeza de pecho judío, 1.600 maravedís; pedido judío, 2.300 maravedís; carne y vino judío, 22.950 maravedís ${ }^{10}$.

De modo que en 1454 , en cuya fecha se efectúan las citadas derramas señoriales, y en 1456, año de confirmación de las ordenanzas de la feria anual, se consolida plenamente en la demarcación bejarana el primer flujo migratorio hebreo, no sólo en la capital de la comarca sino también en algunas poblaciones de la jurisdicción, aunque atendiendo a la documentación de archivo, hasta los años de 1464 y 1480 no podemos constatar con certeza

\footnotetext{
${ }^{7}$ Estatuida el 10 de abril de 1407 por Juan II a Diego López de Estúñiga. A. Martín Lázaro, "Documentos para la Historia de Béjar", Revista de Ciencias Jurídicas y Sociales 6 (1923) doc. 6 págs. $98-99$ (tomado del AHN, Sección Nobleza, Osuna, leg. 214, expte. 10). Sobre las ordenanzas y franquicias de la feria en 1452, 1456 y 1461 véase AHN, Sección Nobleza, Osuna, leg. 216, exptes. 2 y 6; sobre la feria en 1485 véase Archivo General de Simancas [= AGS], Registro General del Sello $[=R G S]$ núm. 1.312 (jul. 1485) f. 23; y AHN, Sección Nobleza, Osuna, leg. 217, expte. 5 ; y sobre la misma en 1489 , Osuna, leg. 218 , expte. 2.

${ }^{8}$ Una de las ordenanzas regula que "ninguna persona, christiano ni judio ni moro de qualquier ley, estado o condiçion que sea, no juegue dados en la ferian; véase AHN, Sección Nobleza, Osuna, leg. 216, expte. 2, recogido por Martín LÁzaro "Béjar" doc. 12 págs. 109-110: pág. 110; J. Muñoz García, "Pañería del siglo XV: Penas a los que jugaran a los dados en la feria de Béjar", Béjar en Madrid 22 (26 nov. 1938) págs. 3-4; y CARRETE Fontes doc. 80 pág. 46.

9 Véanse Martín Lázaro "Béjar" doc. 11 págs. 107-109; y J. Martinez Moro, La renta feudal en la Castilla del siglo XV: Los Stúñiga, Consideraciones metodológicas y otras (Valladolid 1977) págs. 53, 71, 93 y 96, tomado del AHN, Sección Nobleza, Osuna, leg. 215, expte. 10/2.

${ }^{10}$ En 1492 los judíos de Hervás pagan a la aljama de Béjar 16.000 maravedís de la contribución del vino.
} 
la presencia de asentamientos hebreos en otros puntos geográficos del señorío de Béjar.

La referencia a la paulatina repoblación hebrea que experimenta el alfoz bejarano franqueado el meridiano del siglo XV se confirma en las exacciones del "servicio y medio servicio" de los judíos de Castilla (1464-1482) y en los repartimientos de los castellanos de oro para la guerra de Granada (1485-1491), cuyos recuentos relacionan por primera vez la existencia de otros asentamientos hebreos en la comarca.

Así, el listado de las contribuciones económicas judías anota el apunte de "la aljama de la villa de Béjar y los judíos de Hervás" ${ }^{11}$, señal indudable del éxito colonizador hebreo en la tierra de Béjar. No obstante, de la mención exclusiva a los judíos de Ia villa de Béjar y de la población de Hervás no puede concluirse que no hubiese familias hebreas en otras poblaciones del solar bejarano.

Hay que extremar las precauciones a la hora de analizar el contenido de las rentas de los "servicio y medio servicio" de Castilla, así como la contribución económica de los castellanos de oro para la guerra de Granada ${ }^{12}$, para no extraer conclusiones precipitadas, pues percibimos que han sido omitidos de los padrones fiscalizadores algunas de las comunidades judías asentadas en las provincias cacereña y salmantina.

De hecho, los judíos de Hervás no constan en los recuentos de enero de $1488^{13}, 20$ de enero de $1489^{14}$ y enero de $1491^{15} \mathrm{y}$, sin embargo, en esas fechas está constatada la presencia de un nutrido contingente judío en la aldea. En los mismos censos fiscalizadores encontramos poblaciones que figuran bien como jude-

${ }^{11}$ Sobre la aljama de Béjar véase CARRETE Fontes págs. 41-54; M. ${ }^{a}$ Fuencisla Garcia CASAR, El pasado judio de Salamanca (Salamanca 1987) págs. 134-136; Lacave Juderías pág. 267; y M. de Hervás, "Los judíos de Hervás", Carta de Jerusalén 12:66 (1995) págs. 58-70 y 13-14:67-68 (1996-1997) págs. 68-80: 12 pág. 62.

12 Véanse F. CANTERa Burgos en colaboración con C. CARrete, "Los repartimientos de Rabí Jaco Aben Nuñes", Sefarad 31 (1971) págs. 213-250: págs. 241243; M. A. LADERo, "Las juderías de Castilla según algunos "servicios" fiscales del siglo XV", Sefarad 31 (1971) págs. 249-264: pág. 262; y L. Suárez, Documentos acerca de la expulsión de los judios (Valladolid 1964) pág. 66.

13 AGS, RGS, f. 271.

${ }^{14}$ AGS, RGS, f. 219.

${ }^{15}$ AGS, RGS, f. 286. 
rías, bien como aljamas. Concretamente, en las exacciones de 1488 a 1491 es donde detectamos mayores imprecisiones de este tipo. La cacereña Cabezuela del Valle consta como aljama en los tributos de 1472 y 1486 , no así en el censo de 1485 . Belvís de Monroy (Cáceres) es aljama en el recuento de 1485, aparece citada como judería en el de 1488 y de nuevo figura como aljama en el de 1491.

A pesar de estas veleidades censales (¿ligerezas del escribano o errores del copista?), los impuestos judíos de 1464 a 1491 consignan conjuntamente "la aljama de Bejar con los judios de Hervas", de lo que tras una primera lectura se deduce que solamente hay judíos que residen en la villa de Béjar y en la aldea de Hervás. Sin embargo, aunque los repartimientos fiscales sólo hacen mención específica de estos dos lugares, debemos admitir la presencia de familias hebreas, en mayor o menor medida, en otras aldeas de la villa bejarana.

Así, las noticias que proporcionan los documentos que hemos manejado en el archivo del duque de Béjar, en concreto la provisión del duque Álvaro Ir dictada el 21 de enero de 1495 en la que ordena recabar información sobre los bienes que fueron y quedaron de los judíos expulsos del señorío de Béjar, aluden a «esta dicha my villa [de Bejar], como en el mi lugar de Hervas $\mathrm{y}$ en todos los otros mis lugares a donde mora[ba]n los judios y tenian tracto" ${ }^{16}$. La escritura notarial da a entender que, en efecto, hay judíos que residen en otras aldeas del feudo bejarano, en algunas de las cuales -sugiere el escrito- los miembros de la comunidad hebrea han efectuado transacciones comerciales, o bien tienen bienes muebles y raíces, pero no alcanza a revelar la identidad topográfica hebrea del alfoz de Béjar.

Otro documento coetáneo del mismo tipo tampoco nos permite despejar la duda sobre las poblaciones bejaranas que albergan moradores hebreos en el ocaso del siglo XV. El 23 de enero de 1495 los contadores de la casa de los Zúñiga instruyen un mandamiento dirigido a "todos los vezinos desta villa de Bejar y de los lugares de Hervas, e Candelario, e Beçedas, e Gilbuena, e Solana, e Santibañes, e Sorihuela, e la Cabeça, e Fuentes, y todos los otros lugares de la nuestra de la dicha villa y de otras partes» ${ }^{17}$, en el cual requiere al vecindario que dé noticia obliga-

${ }^{16}$ AHN, Sección Nobleza, Osuna, leg. 218, expte. 4/1.

${ }^{17}$ AHN, Sección Nobleza, Osuna, leg. 218, expte. 3/1, de donde lo toma Carrete Fontes doc. 93 págs. 51-52. 
da del paradero de los bienes muebles y raíces abandonados por los judíos expulsos y denuncie a sus actuales propietarios; pero estos mandamientos siguen sin revelarnos las poblaciones donde residen y tienen sus heredades los judíos bejaranos.

Otro de los textos documentales que hemos hallado -el interrogatorio elaborado por la contaduría en 1495-inquiere sobre el paradero de los bienes raíces que

tovieron los judios desta villa de Bejar y del lugar de Hervas y de los otros lugares de su tierra y jurediçion [...], quales y quantas casas los $\mathrm{d}[\mathrm{ic}]$ hos judios tenya[n] y toviero[n] en los ot[r]os lugares desta d[ic]ha villa de Bejar, asy como son Candelario, Beçedas, Gilbuena, Solana, Santybañes y q[ua]lesq[ui]r ot[r]os lugares en q[ue] los d[ic]hos judios tovyesen casas o casas trojes en q[ue] encerraria su pa[n] ${ }^{18}$.

En primera instancia, el documento señorial nos permite plantearnos la posible presencia de familias o de pequeñas comunidades hebreas no sólo en las cinco localidades bejaranas mencionadas, sino también en otras no citadas en las escrituras; pero de ningún modo nos confirma que residiesen judíos o tuviesen propiedades en todas y cada una de ellas.

Es evidente que además de en la villa de Béjar y Hervás hay asentamientos judíos en otros lugares de la comarca, pero disentimos del criterio de los historiadores que en las últimas décadas tienden a ubicar comunidades hebreas en buena parte de los poblados del señorío bejarano ${ }^{19}$. A la luz de las escrituras notariales no se puede asegurar el establecimiento de núcleos o familias hebreas en casi todos los pueblos bejaranos, como veremos seguidamente.

La gavilla de textos documentales que hemos consultado en el archivo ducal nos informa que David Caçes tiene una casa en propiedad en Gilbuena, que intenta recuperar a su regreso del exilio $^{20}$, pero no sabemos si reside en la aldea o en la villa de

${ }^{18}$ AHN, Sección Nobleza, Osuna, leg. 266, expte. 74; recogido por Carrete Fontes doc. 94 págs. 52-54.

${ }^{19}$ E. C. de Santos CANalejo, La historia medieval de Plasencia y su entorno geo-histórico: La sierra de Béjar y la sierra de Gredos (Cáceres 1986) págs. 524526; García Casar Salamanca pág. 161; y A. Avilés Amat, Judios de Béjar: Consideraciones sobre su vida e historia (Béjar 1994) pág. 38.

${ }^{20}$ AHN, Sección Nobleza, Osuna, leg. 266, expte. 74; citado por Carrete Fontes pág. 48. 


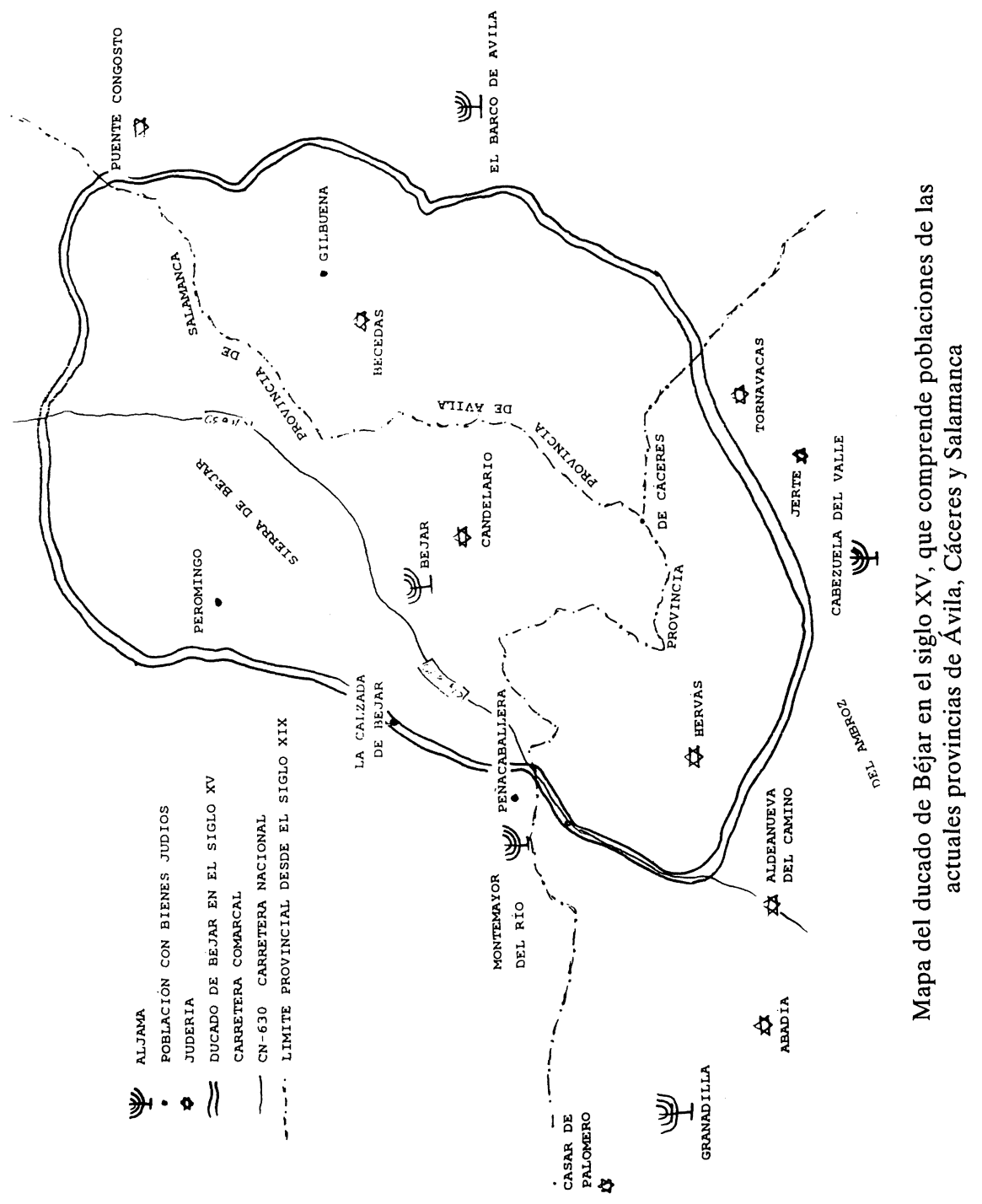


Béjar. Del mismo modo, en las inmediaciones de Becedas (Ávila) registramos en 1291 el topónimo «Sancho de Orabuena» ${ }^{21}$. ¿Acaso hace referencia a la presencia de algún judío en el lugar en el siglo XIII? Igualmente tenemos noticia de que rabí Simuel es propietario de un palomar ubicado en la aldea de Peromingo y de una casa con corrales sita en la villa de Béjar, sin embargo, el rabino reside en Hervás ${ }^{22}$. Sobre la comunidad hebrea de Hervás hemos publicado recientemente un extenso artículo y no es menester entrar ahora en más detalles ${ }^{23}$. También localizamos una familia hebrea viviendo en la población salmantina de La Calzada de Béjar ${ }^{24}$. En Candelario reside una pequeña comunidad hebrea en el último tercio del siglo $\mathrm{XV}$, como tendremos oportunidad de analizar en su momento.

En fin, a la vista de los datos mencionados, cabe decir que los judíos del señorío bejarano -ducado a partir de 1488- se afincan mayoritariamente en la villa de Béjar donde establecen la aljama, en menor número en la aldea de Hervás, y también en las localidades de Candelario y La Calzada, quedándonos con la incertidumbre de Becedas. En cuanto a los lugares donde los judíos poseen propiedades y bienes muebles y raíces, además de las consignadas, hallamos las poblaciones de Gilbuena y Peromingo.

Por consiguiente, aunque las derramas castellanas de 1464-1485 mencionan exclusivamente "la aljama de Bejar con los judios de Hervas", también cabe incluir en los recuentos fiscalizadores las poblaciones de Candelario y La Calzada, sin descartar otros núcleos poblacionales del señorío no revelados en las escrituras. En este punto, el sistema contributivo de los judíos del alfoz de Béjar de ningún modo refleja su distribución geográfica, ya que

${ }^{21}$ Archivo Municipal de Béjar, sección $1{ }^{\text {a }}$ leg. 1, núm. 10, publicado por A. Martín Lázaro, "Colección Diplomática de la ciudad de Béjar", Revista de Ciencias Jurídicas y Sociales 4 (1921) págs. 449-450; J. MuÑoz GARcía, "Límites que tuvo la antigua tierra de Béjar", en Antiguas ordenanzas para la conservación del Monte Castañar de la villa de Béjar y para el buen gobierno de ella (Béjar 1940) pág. 176; y A. Barrios García y A. Martín Expósito, Documentación medieval de los archivos municipales de Béjar y Candelario (Salamanca 1986) doc. 20 págs. 50-51.

${ }^{22}$ AHN, Sección Nobleza, Osuna, leg. 266, expte. 74.

${ }^{23}$ El padrón hebraico se conserva en AHN, Sección Nobleza, Osuna, leg. 267, expte. 32 ; recogido en mi artículo "Hervás" pág. 63.

${ }^{24}$ El mesón y las casas propiedad de la conversa Isabel González «la salamanquesa", vecina de La Calzada de Béjar, fueron requisados en 1494 por el receptor de bienes judíos, Juan de Aguirre; AGS, RGS, núm. 1.887 (15 mayo 1494) f. 209 
los padrones fiscales no reseñan localidades que sabemos tienen comunidades hebreas, como por ejemplo, Candelario y La Calzada. Por el contrario, los recuentos reflejan en su verdadera dimensión la capacidad económica de la aljama, juderías y comunidades hebreas del alfoz bejarano, que queda cifrada en la siguiente contribución ${ }^{25}$ :

$\begin{array}{lrrr}\text { año } & \underline{\text { mrs. }} & \text { año } & \underline{\text { mrs. }} \\ 1464 & 10.000 & 1485 & 206 \\ 1472 & 8.000 & 1488 & 55.207 \\ 1474 & 7.000 & 1489 & 58.920 \\ 1479 & 7.000 & 1490 & 50.370 \\ 1482 & 7.000 & 1491 & 52.920\end{array}$

Por lo que respecta a la comunidad hebrea de Candelario, las Ordenanzas del concejo municipal de la aldea, expedidas por el dignatario Álvaro de Zúñiga el sábado 27 de mayo de $1488^{26}$ y conservadas en el Archivo Municipal de la villa, nos proporcionan la primera noticia específica. En el apartado número 38 de las citadas Ordenanzas, el señor de Béjar redacta un epígrafe titulado "Capítulo de los judíos» en el que se dice:

Otro sí, hordenamos y tenemos por bien que ningun vezino e vezina e apaniguado no sea osado de conprar ni tratar con judio ni judia en domingo ni en Pasqua ni dia de Santa Maria ni dia de Ihesuchristo so pena de un rreal porques deserviçio de nuestro señor ${ }^{27}$.

A tenor del artículo ducal, es evidente que en la aldea candelariense reside, incuestionablemente, un colectivo hebraico cuyo volumen de población consideramos que debe ser inferior al de la comunidad judía de Hervás ${ }^{28}$, de ahí que no figure en ninguna

25 Véanse Cantera Burgos y Carrete "Aben Nuñes" págs. 241-243; Ladero "Servicios" pág. 262; SuÁrez Expulsión pág. 66; y AGS, RGS, censos de 1488 1491.

26 Según Barrios García y Martín Expósito Documentación pág. 138 nota 24: "es muy probable que este documento corresponda al año 1480".

27 Véase Barrios García y Martín Expósito Documentación pág. 148, tomado del Archivo Municipal de Candelario [= AMC], leg. 16, núm. 10: «Hordenanzas deste lugar de Candelario confirmadas por el señor duque de Bejar, don Francisco en 10 noviembre de 1533", f. 11v; y leg. 16, núm. 11: "Ordenanzas y confirmaciones del lugar de Candelario" (1480-1620) f. 17.

${ }^{28}$ En Hervás había una cifra aproximada de unas 45 personas o cabezas de familias hebreas. 


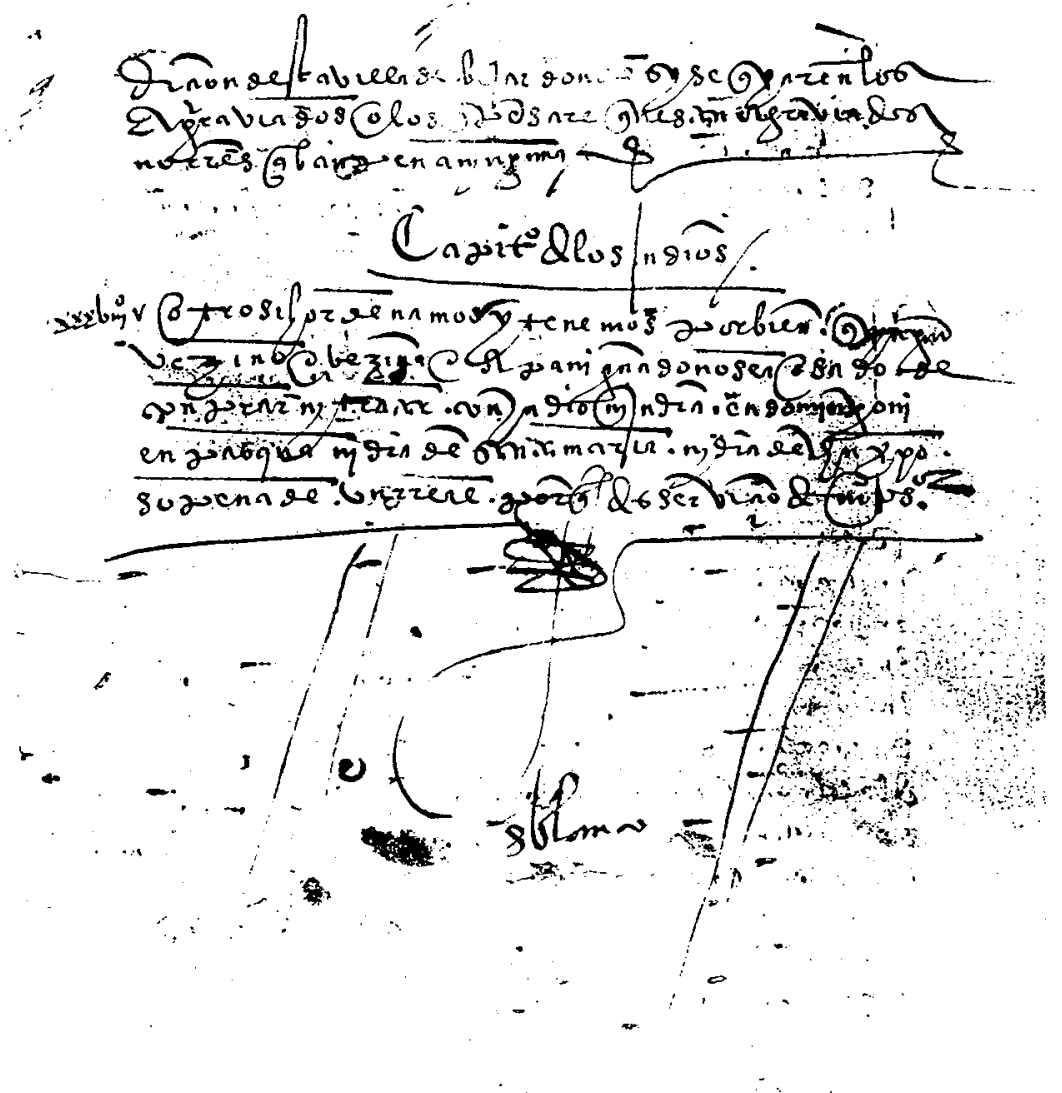

"Hordenanzas deste lugar de Candelario ...", AMC, leg. 16, núm. 10, f. 11v (vid. texto y nota 27) 
de las exacciones bejaranas enunciadas. Es verosímil que los judíos de Candelario participasen con una pequeña bolsa económica en la fiscalización de los tributos judiegos de la villa y tierra, pero de ningún modo satisfacen su contribución separadamente de la aljama de Béjar. En este sentido, L. Suárez atribuye erróneamente a los judíos de Candelario las derramas judiegas de Candeleda, población perteneciente al obispado y provincia de Ávila ${ }^{29}$.

Desconocemos igualmente la fecha de emplazamiento de la comunidad judía en Candelario. Puede ser coetánea de la de Hervás, asentada ésta última en el ecuador del siglo XV, o quizá de época posterior. La comunidad hebrea de Candelario pudo formarse a partir de las favorables condiciones fiscales que el dignatario de Béjar oferta a judíos y cristianos, aunque no hay datos específicos sobre el particular.

Es sabido que la casa de Alba otorga franquicias especiales a los hebreos -y cristianos- que trasladan su domicilio a las villas y aldeas de su jurisdicción, y también una vivienda y una tierra de viñedos ${ }^{30}$. Así, en los primeros años del último tercio del siglo $\mathrm{XV}$ asistimos al desplazamiento de familias hebreas radicadas en lugares de realengo hacia las tierras que la nobleza posee en Extremadura y Salamanca ${ }^{31}$. No sólo los territorios del duque de Béjar reciben población hebrea en estas fechas, sino también las villas y poblados que la casa de Alba tiene en Salamanca (Alba de Tormes) y Cáceres (Granadilla y Coria).

La historia de la comunidad hebrea de Candelario, como la del resto de las comunidades hebreas de la villa y tierra, está ligada indefectiblemente a la aljama de Béjar. En cuanto que institución político-religioso, la aljama bejarana regula las normas jurídicas que rigen la vida de todas las comunidades hebreas que habitan en el alfoz señorial y atesora en sus arcas los tributos fiscales de los judíos de Candelario.

Apenas encontramos otras noticias en el archivo ducal. Según el contenido del "Capítulo judío" candelariense recogido en las

\footnotetext{
${ }^{29}$ Véase SuÁrez Expulsión pág. 66; en cambio, en la pág. 78 consigna la judería de Candeleda (Ávila) y no la de Candelario (Salamanca).

${ }^{30}$ A. Vaca y J. A. Bonilla, Salamanca en la documentación medieval de la Casa de Alba (Salamanca 1984) docs. 71, 80 y 83.

${ }^{31}$ VACA y Bonilla Salamanca docs. 71, 80 y 83. Judíos de Cáceres se trasladan a lugares de señorío en 1489 porque "non pagan nin contribuyen en tanta suma de mrs. como en esta dicha villan; cf. Suárez Expulsión doc. 150 pág. 353 tomado del AGS, RGS (15 mar. 1491) fols. 90 y 550.
} 
Ordenanzas municipales, es factible que en los prolegómenos del decreto de expulsión, por razones que se nos escapan, la comunidad hebrea de Candelario no gozase de la confianza del dignatario feudal. Quizá la causa resida en ciertas asperezas de ámbito social o político, producidas entre judíos y cristianos. Es evidente que el señor de Béjar aconseja a los vasallos de Candelario que no hagan negocios ni mantengan relaciones comerciales con los judíos en el transcurso de la semana santa y demás festividades religiosas, cuya disposición -que no sabemos si se cumple al pie de la letra- lesiona los intereses del comercio hebreo.

Esta ordenanza coercitiva está inspirada en el Ordenamiento de Valladolid de enero de 1412 , si bien el precepto regio sólo restringe la venta de determinados artículos alimenticios a los cristianos, al margen de los días de fiestas religiosas ${ }^{32}$.

En los últimos años de la década de los 80 del siglo XV detectamos el enrarecimiento de las relaciones sociales entre las comunidades hebrea y cristiana de pueblos cacereños y salmantinos ubicados en las inmediaciones del territorio del señorío bejarano, como la villa de Granadilla, donde se señala un apartamiento de barrios en 1489, Casar de Palomero (Cáceres) ${ }^{33}$ y Ciudad Rodrigo (Salamanca) ${ }^{34}$.

¿Acaso la publicación del mandamiento señorial está motivada por algún acontecimiento extraordinario acaecido contra la comunidad hebrea de Candelario que no hemos detectado en los textos escriturales? Ahora bien: ¿por qué el señor de Béjar sólo aplica medidas restrictivas contra los judíos de Candelario y no contra todas las comunidades hebreas del alfoz bejarano? La

\footnotetext{
${ }^{32}$ Este precepto se aplica en Granadilla en 1489 con ligeras variantes: "Otro sy ordeno e mando que ningund judio nin moro nin mora nin judia non sean osadas de vender nin vendan en publico nin secreto cosas de comer qualesquier que sean a ningunos nin algunos christianos so las penas contenidas en la ley real que çerca desto fabla»; Archivo de la Casa de Alba, leg. "Granadilla", f. 26, recogido por E. Escobar PRIETo, "Granadilla", Revista de Extremadura 7 (1905) págs. 379-388: págs. 386-388; y P. LEón TELlo, "La judería extremeña de Granadilla", en Exilio y Diáspora: Estudios sobre la historia del pueblo judío en homenaje al Profesor Haim Beinart (Jerusalén 1991) págs. 146-156: págs. 154156.

33 Véase M. de Hervás, "Calumnias antijudías cacereñas", en Actas de las Jornadas Extremeñas de Estudios Judaicos (Badajoz 1996) págs. 205-225.

${ }^{34}$ Garcia Casar, Salamanca págs. 151-152 y 172; F. Sierro Malmierca, Judios, moriscos e Inquisición en Ciudad Rodrigo (Salamanca 1990) págs. 34-35.
} 
aljama de Béjar y los judíos de Hervás no conocen ninguna disposición señorial que limite la libertad de movimientos en el comercio hebreo, o que condicione la práctica de los preceptos mosaicos. ¿Es, quizá, la atmósfera de inestabilidad antijudía que se respira en Candelario lo que motiva el ligero receso económico en las contribuciones judiegas de 1490 ?

¿En qué barrio se establecen los judíos de Candelario? Debemos señalar previamente que el primer asentamiento urbano de la aldea tiene lugar en el albor del siglo XIII, en torno al desaparecido barrio Somero -hoy destinado a labores agrícolas- en el paraje más elevado del lugar denominado popularmente barrio de Arriba. En su entorno natural, los pobladores cristianos acomodan en los siglos XIV y XV el primer espacio urbanístico destinado a viviendas, formando la Plaza y las calles Cascajal, de la Hoya, Cantimplora, Corredera, Hospital, de la Plata, Iglesia y de la Hormiga, que albergan los edificios civil (casas consistoriales), sanitario (hospicio) y religioso (santuario parroquial).

Este es el perfil geográfico que encuentran los judíos a su llegada a Candelario, empero no hay ninguna noticia documentada sobre las casas, calle o barrio donde se instala la comunidad hebrea. Tampoco existen datos sobre la creación de un espacio marginal destinado a la reclusión de la comunidad judía. Sabemos que la comunidad hebrea experimenta ciertas restricciones, mínimas, en la década de los 80 del siglo XV, pero no hay razón para convenir que las pocas familias hebreas que habitan en la población vivan aisladas en una barriada o judería. Es de suponer, por tanto, que los judíos conviven -coexisten- con los cristianos en las casas del barrio de Arriba.

La noticia de la documentación de una comunidad hebrea en Candelario ha dado pie en la última década a la consideración de un barrio de la judería - hasta ahora desconocido por la historiografía moderna-, que algunos autores han emplazado sin fundamento en el barrio de Arriba. Del geógrafo salmantino E. García Zarza toma C. García Martínez ${ }^{35}$ la referencia que ubica la judería candelariense en "lo que ahora se conoce como el barrio de los Perros", cuya arteria urbana viene a coincidir, según los

\footnotetext{
${ }^{35}$ C. Garcia Martinez, Guía de Béjar y Candelario (Béjar 1991) pág. 88, sin precisar la fuente bibliográfica; y Candelario, parada y fonda (Béjar 1993) pág. 51.
} 
testimonios orales que hemos recogido en la localidad, con la actual calle de Margarita Muñoz ${ }^{36}$. No obstante, no hemos podido constatar documentalmente el citado emplazamiento hebreo, que creemos es invención moderna.

Por el contrario, consideramos que la expresión «de los Perros", aplicada al conjunto de casas propincuas a la iglesia parroquial, hace referencia a una barriada de ámbito marginal ocupada en los siglos XVI al XVIII por un reducto social minoritario que no cuenta con las simpatías del resto del vecindario.

En favor de nuestra tesis interviene L. Harguindey Muñoz ${ }^{37}$ - párroco de Candelario-, que nos proporciona amplios detalles sobre la identidad de los moradores, al expresar que los vecinos del barrio de los Perros habitan una veintena de casas en mal estado de conservación y son rechazados por los miembros de las cofradías del barrio de Abajo "acusándoles de falta de honradez", o lo que es lo mismo: que adolecen de crédito cristianego. En su propia defensa -argumenta el sacerdote Harguindey-, los vecinos del barrio de Arriba aplican el mismo rasero a sus rivales al no admitir en sus congregaciones a los vecinos del barrio de Abajo, arguyendo que el descrédito está en su gremio social.

Hagamos un breve inciso en nuestro recorrido para glosar que el notable incremento demográfico experimentado en Candelario en el albor del Renacimiento y a finales del Barroco, propicia la expansión urbana y la construcción de nuevas arterias por la ladera noreste de la población.

Desde la calle Corredera, extremo del poblado, se descuelgaa las calles Arrabal, Abajo, Fuente Chica, Mayor, Palomas, Perales, Regadera, del Río, que conforman el barrio de Abajo. Así pues, el Candelario del siglo XVII está fragmentado en dos distritos urbanos, el barrio de Arriba y el barrio de Abajo, cuyos moradores no están en muy buena sintonía. Parece ser que las disensiones entre los vecinos de ambas barriadas emanan de las ambiciones políticas que se disputan los dos clanes o familias, los Mateos y los Ricos ${ }^{38}$, en su pretensión de controlar los resortes de la vida municipal y de las hermandades cofrades. Ahora bien,

\footnotetext{
${ }^{36}$ El dato está recogido en un mapa turístico municipal.

37 Recogido por García Martínez Candelario pág. 50. El sacerdote no cita sus fuentes, que creemos corresponden a AMC, leg. 69, núm. 15.

${ }_{38}$ AMC, leg. 349, núm. 2: "Escritura de concordia entre el corregidor de Bejar y el lugar de Candelario sobre nombramientos de oficiales del concejon (1718).
} 
¿cuál de las dos entidades corporativas habita en el barrio marginal de los Perros?

En las escrituras protocolarias de Candelario que hemos consultado en el Archivo Histórico de Salamanca ${ }^{39}$-las primeras noticias son de principios del siglo XVIII- y en los libros eclesiales de la parroquial de Nuestra Señora de la Asunción - del siglo XVII- percibimos que las dos familias antagonistas viven entremezcladas en las calles y plazas de la población, aunque hay una cierta tendencia generalizada en el clan de los Mateos, en franca minoría social, a ocupar las calles del barrio de Arriba, en tanto que la estirpe de los Ricos, que duplica en número a sus oponentes, se extiende mayoritariamente por la modernizada barriada de Abajo.

Por otra parte, nos preguntamos de dónde procede el injurioso epíteto perruno y bajo qué circunstancias tiene lugar su incorporación en el medio rural. Puede tratarse del reflejo en las capas rurales menos cultivadas del sentimiento antijudío que se expande por la Península en el último tercio del siglo XVI, impulsado sobre todo por la implantación de los estatutos de limpieza de sangre en ayuntamientos y cofradías por voluntad de la corona, los señores feudales y los estamentos clerical y laico ${ }^{40}$, y que sólo sirven para levantar barreras sociales, frenar la asimilación del converso y airear sus tachas hebraicas.

A esta serie de condicionantes político-religiosos aporta su grano de arena la difusión por el ducado de Béjar, vía Salamanca, de la sátira teatral que relata «el pleito de los judíos con el perro de Alba y de la burla que les hizo" ${ }^{41}$, muy celebrada en la Península, pieza esta que contribuye notablemente a caldear el ambiente anticonverso comarcano. En palabras de $\mathrm{H}$. Beinart «el perro es el símbolo de la distinción que hay que hacer entre lo

39 Archivo Histórico Provincial de Salamanca, Escribanía Marcos Martín (1699-1741) legs. 1.132-1.136; Escribanía A. Vallejera (1741-1757) leg. 1.137 y (1759-1803) legs. 1.138-1.143, Catastro de Ensenada, libros 557-562.

${ }^{40}$ Cofradías de Béjar, Hervás y Baños de Montemayor, poblaciones del señorío, incorporan en los siglos XVI y XVII estatutos de limpieza de sangre para impedir el acceso de los descendientes de judíos.

${ }^{41}$ Reproducción facsimilar del ejemplar de la Biblioteca Nacional (Madrid) en la sección anónima "Colección de pliegos sueltos", Revista de Archivos, Bibliotecas y Museos 47 (1926) págs. 409-416; véase también A. Huarte Y ECHENIQUE, Colección de pliegos sueltos, agora de nuevos acabados, recogidos y anotados por Vicente Castañedo (Madrid 1929) págs. 65-72. 
bueno, identificado con lo cristiano, y lo malo, que es el judío hipócrita y engañoso" ${ }^{42}$, en nuestro caso, el judeoconverso.

En el caldo de cultivo rural, el denuesto "perro de Alba" impregna los rudos modos de expresión del hombre de la calle, que utiliza para descalificar ante la opinión pública a los taimados conversos. Así pues, en la órbita de la desafección contra los ciudadanos de extracción hebraica gravita la expresión "de los perros", que adquiere resonancia especial en los lugares del ducado bejarano con población conversa.

Sirvan como botón de muestra tres ejemplos ilustrativos, espigados en diversos pueblos del alfoz de Béjar. Al camino que une el antiguo barrio de la judería de Béjar -ahora conversocon el puente de San Albín, a través de la desaparecida puerta de la Judería ${ }^{43}$ o Puerta Nueva, la llaman «la cuesta de los Perros" ${ }^{44}$. A mediados del siglo XVI, a una familia de origen hebreo vecina de Béjar y oriunda de Valdefuentes de Sangusín (Salamanca) se la conoce como "los zorros de Alba " ${ }^{45}$. En Hervás se utilizan con profusión los vocablos "perro" y "perro de Alba" para motejar a los cristianos nuevos, en especial en el período transcurrido entre 1619 y $1712^{46}$.

Con la misma perspectiva consideramos que se debe contemplar el uso del término «barrio de los Perros» en Candelario. En este caso específico, la adjetivación se emplea para desacreditar a los moradores afincados en una calle concreta del barrio de Arriba, la calle de Margarita Muñoz, donde habita un sector marginal de la población, la estirpe de los Mateos, que no goza de crédito popular, quizá porque son descendientes de judíos ${ }^{47}$.

${ }^{42}$ H. Beinart, Los judios en España (Madrid 1992) pág. 218.

${ }^{43}$ J. C. Aguilar Gómez y M. ${ }^{a}$ del C. Martín Martín, Aproximación a la historia medieval de Béjar (Salamanca 1989) pág. 90.

${ }^{44}$ C. GaRcia MaRTinez, Inventario de los lugares bejaranos: sus nombres, su historia, su ambiente (Madrid 1984) pág. 24.

${ }^{45}$ Archivo de la Real Chancillería de Valladolid, Pleitos Civiles, Quevedo, leg. 1.643-1.

${ }_{46}$ Archivo Histórico Provincial de Cáceres, Prtlos., leg. 2.388, "Apartamiento, 12 de diciembre de 1619"; leg. 1.090, "Apartamiento, 21 de noviembre de 1655", f. 7; y leg. 922, "Apartamiento, 22 de abril de 1712", f. 85 .

${ }^{47}$ A. Avilés Amat me comunica que, en su opinión, el "barrio de los Perros" es el barrio judeoconverso, cuya denominación popular toma cuerpo con posterioridad al edicto de expulsión. 
No es fruto de la casualidad la instalación de una rústica y visible cruz de piedra a la entrada de la barriada de los Perros, construida probablemente en un período muy posterior al edicto de expulsión, que da su nombre a la calle Fuente de la Cruz de Piedra, y la acomodación de copiosas cruces pétreas y del acróstico cristiano $J H S$ en los dinteles de las viviendas de las casas números 16,26 y 28 en el año de 1762 , período éste en que empiezan a remitir las conculsiones político-sociales de los gremios corporativistas ${ }^{48}$.

Concluimos nuestras noticias con otros apuntes no menos interesantes que afectan de modo tangencial a la comunidad hebrea de Candelario, relacionados en este caso con la extinción oficial del credo mosaico en el ducado de Béjar.

Con el edicto de expulsión de los judíos, la contaduría de Béjar elabora un amplio muestrario de mandamientos y provisiones, de los cuales hemos dado noticia en páginas precedentes, resolviendo que el cuerpo de bienes abandonados por los exiliados bejaranos son propiedad señorial. En algunos textos se menciona la población de Candelario, pero nada conocemos sobre la identidad de los miembros de la comunidad judía, las propiedades abandonadas por los extrañados, cómo afrontan el exilio, los problemas de las conversiones o el destino de los bienes raíces judíos. Un tibio haz de luz, sin embargo, se arroja en el capítulo relacionado con el universo criptojudío.

Al igual que acontece en buena parte de la Península, los judíos del señorío bejarano simulan su conversión al cristianismo y en secreto siguen practicando los preceptos de la ley de Moisés. Su manifiesta herejía contra la religión católica les conduce irremisiblemente al tribunal de la herética pravedad de la provincia de León, hecho que tiene lugar en los primeros meses de 1514.

En los expedientes jurídicos de la Inquisición de Llerena se habla de procesos de fe contra judaizantes de la villa de Béjar,

${ }^{48}$ En 1754, fray Juan Román, predicador del convento de San Francisco de Béjar, y el juez episcopal de Plasencia promueven una concordia entre los Mateos y los Ricos, según la cual los Ricos obtienen los cargos municipales y el control de las mayordomías cofrades durante dos años consecutivos y los Mateos le suceden al siguiente año; AMC, leg. 69, núm. 15: "Escritura de concordia entre las parttes de los Ricos y de los Mattheos de el lugar de Candelarion (1754). 
Hervás y otros lugares de la jurisdicción no especificados en los textos. También se hace referencia a diversos enjuiciamientos inquisitoriales efectuados in absentia, confiscación de bienes, relajados ${ }^{49}$, etcétera. Sabemos incluso que las reclamaciones económicas que la casa de Béjar efectúa al pesquisidor de bienes judíos fuerzan la cesión por los Reyes Católicos al duque de Béjar, Álvaro II, de la tercera parte de las propiedades embargadas por la Inquisición a los judaizantes de la tierra de Béjar ${ }^{50}$. Pero, ¿hay familias criptojudías en Candelario? No lo sabemos a ciencia cierta. No obstante, en las actas del tribunal de la Inquisición llerense de 1588 constan los expedientes disciplinarios de los candelarienses Juan, criado de Pedro González, y Picarcelo ${ }^{51}$, ambos procesados por los inquisidores extremeños porque, según las declaraciones de los testigos anónimos, reniegan de la religión cristiana en uno de sus viajes a Berbería. Ahora bien, nada se nos dice de su credo religioso. ¿Eran judeoconversos nativos del lugar?

\section{RESUMEN}

En el siglo XV se establecen comunidades hebreas en el señorío de Béjar: Hervás (Cáceres), Candelario y La Calzada (Salamanca). Poco tiempo antes de la expulsión, el duque de Béjar impone ligeras restricciones comerciales a los judíos de Candelario. Es posible que tras el edicto de expulsión los conversos de Candelario habitasen en el "barrio de los Perros".

\section{SUMMARY}

In the fifteenth century, Spanish-Jewish communities settled in the area of Béjar: in Hervás (province of Cáceres), Candelario, and La Calzada (province of Salamanca). Shortly before the 1492 Edict of Expulsion, the Duke of Béjar imposed light commercial sanctions or restrictions on the Jewish population of Candelario. It may be that after the Edict, Candelario's converso population dwelled in "El Barrio de los Perros" ('The Dog District').

${ }^{49}$ AHN, Inquisición, Hacienda, legs. 4.573/1 y 4.573/3.

${ }^{50}$ AHN, Sección Nobleza, Osuna, leg. 218, expte. 4/2.

${ }^{51}$ AHN, Inquisición, leg. 1.988, expte. 25, fols. 6 y 9. 